Tema: Solidificação / Lingotamento

\title{
ESTUDO DO ESCOAMENTO DO AÇO LÍQUIDO NO DISTRIBUIDOR DO LINGOTAMENTO CONTÍNUO 01 DA APERAM INOX AMERICA DO SUL*
}

\begin{abstract}
João Geraldo Alves ${ }^{1}$ Roberto Parreiras Tavares ${ }^{2}$

\section{Resumo}

A qualidade interna das placas obtidas no lingotamento contínuo é afetada pelas características do escoamento do aço líquido no distribuidor. O modelamento matemático é uma ferramenta muito utilizada para estudar o escoamento do aço líquido e a eficiência do uso de modificadores de fluxo na separação de inclusões do aço no distribuidor. O objetivo deste trabalho é determinar, através da modelagem matemática, uma configuração de barragem e dique que possa proporcionar uma melhor qualidade do aço lingotado. Essa modelagem utiliza recursos do software comercial ANSYS CFX, que é um software baseado no método dos volumes finitos para a solução de problemas da dinâmica dos fluidos computacional (CFD Computational Fluid Dynamics). A utilização de barragens e diques permitiu uma melhora significativa nas condições de escoamento do aço, o que possibilitará uma melhor flotação e separação das inclusões, com um aumento no tempo de residência do aço no distribuidor, quando comparados com o projeto do distribuidor atualmente em uso.
\end{abstract}

Palavras-chave: Distribuidor; Simulação numérica; CFX; Inclusão.

\section{STUDY OF LIQUID STEEL FLOW IN THE SLAB CASTER 01 TUNDISH OF APERAM STAINLESS STEEL SOUTH AMERICA}

\section{Abstract}

The slab internal quality obtained in the continuous casting is affected by flow characteristics of liquid steel flow in the tundish. The mathematical modeling is a very useful tool to study the steel flow and the efficiency of the use of the flow modifiers in the inclusion separation of the tundish steel. The objective of this study was to determine, through the mathematical modeling, one configuration of dam and weir that possibility a better quality of the casted products. This modeling uses features of commercial software Ansys-CFX, which is software based in the finite elements methods for the solutions of CFD problems (Computational fluid dynamics). The use of dams and weirs permitted a significant improvement in the steel flow condition, that will possibility a better inclusion flotation and separation, with a increasing of residence time the steel in the tundish, when it compared with the design of the tundish currently in use

Keywords: Tundish; Numerical simulation; CFX; Inclusion.

1 Engenheiro Metalurgista, Gerência de Solidificação, Aperam Inox América do Sul; Estudante pósgraduação, Departamento de Engenharia Metalúrgica e de Materiais, Universidade Federal de Minas Gerais, Belo Horizonte, MG, Brasil.

2 Professor Associado, Departamento de Engenharia Metalúrgica e de Materiais, Universidade Federal de Minas Gerais, Sócio da ABM, Belo Horizonte, MG, Brasil.

* Contribuição técnica ao 450 Seminário de Aciaria - Internacional, 25 a 28 de maio de 2014, Porto Alegre, RS, Brasil. 


\section{INTRODUÇÃO}

No processo do lingotamento contínuo de aço, o distribuidor é um reator intermediário entre a panela e o molde, que tem como funções básicas de servir de reservatório para possibilitar trocas de panelas e distribuir o aço para um ou mais veios (moldes). Nos últimos anos esse reator têm-se tornado em um importante local que possibilita a remoção de inclusões não-metálicas e homogeneização térmica do aço. A otimização do escoamento do aço no distribuidor tem como objetivo maximizar a remoção de inclusões, evitando, ao mesmo tempo, problemas de escoamento como turbulências superficiais excessivas, curto circuitos, zonas mortas e formação de vórtices. O escoamento do aço no distribuidor deve proporcionar um fluxo de modo a direcionar as inclusões para a superfície superior, com um nível ótimo de turbulência, evitando ao mesmo tempo, emulsificação e arraste de novas inclusões.

Em função da importante contribuição do distribuidor na limpidez do aço, diversos estudos [1,2] apresentam os benefícios da utilização dos dispositivos alteradores de fluxo, na otimização do escoamento do aço líquido no distribuidor do lingotamento contínuo. Todos os estudos relativos à utilização dos modificadores de fluxo procuram um acréscimo no tempo de residência médio do aço no distribuidor por meio do aumento do escoamento pistonado, objetivando favorecer a flotação das inclusões não-metálicas e, consequentemente, aumentar a limpidez das placas produzidas no lingotamento contínuo. Neste trabalho são desenvolvidas simulações numéricas focadas no estudo das curvas de distribuição do tempo de residência (DTR) e na flotação de inclusões, para o distribuidor do lingotamento contínuo número 01 da APERAM Inox América do Sul, na condição do projeto atual (sem modificadores de fluxo) e com modificadores de fluxo em diferentes posições. A barragem e o dique têm sido aplicados em conjunto para produzir os resultados desejados no processo de lingotamento contínuo. Muitos estudos [3] mostram claramente que as condições para a flotação e separação das inclusões não metálicas no distribuidor, tais como a ausência de curto circuito, uma região de turbulência confinada próxima à entrada do fluxo de aço proveniente da panela, alto tempo de residência médio, etc., podem ser efetivamente criadas utilizando uma combinação apropriadas desses modificadores de fluxo no distribuidor.

A obtenção de um padrão de escoamento que possibilita uma melhoria na flotação das inclusões é um fator importante estudado neste trabalho. De acordo com Sinha e Sahai [4], nos distribuidores do lingotamento contínuo atuais, é fundamental que se concilie alta produtividade e qualidade, produzindo aços com maior limpidez possível.

De acordo com Zhang e Thomas [5], as principais fonte de geração de inclusões são: reações químicas (desoxidação e reoxidação); reações de tratamento da morfologia das inclusões realizadas de forma imprópria; arraste de escória, de pós de cobertura do distribuidor e de fluxantes no molde; erosão ou desgaste dos refratários utilizados na panela e no distribuidor. É de suma importância conhecer os efeitos deletérios da das inclusões nas propriedades doso aços. De forma geral, tanto óxidos quanto sulfetos deterioram as propriedades mecânicas dos aços, principalmente a ductilidade, tenacidade, resistência à fadiga e a usinabilidade do metal. Óxidos sólidos (alumina ou aluminato de cálcio, por exemplo) podem causar entupimento nas válvulas durante o lingotamento contínuo, ocasionando até a interrupção do processo. Entre os problemas causados pelas inclusões, destaca-se

\footnotetext{
* Contribuição técnica ao 45 Seminário de Aciaria - Internacional, 25 a 28 de maio de 2014, Porto Alegre, RS, Brasil.
} 
como um dos mais periculosos, a falha da peça durante a aplicação (desgaste prematuro, quebra, trincas, etc.).

As inclusões são menos densas que o aço líquido e, consequentemente, têm que ser removidas pela flotação até a interface aço/escória. Esta interface dever possuir a capacidade de capturar a inclusões oriundas do metal líquido. Para otimizar a flotação das inclusões é de suma importância que se estude e modele o escoamento dentro do distribuidor, utilizando modificadores de fluxo (inibidores de turbulência, barragem, dique, etc.).

O objetivo deste trabalho foi determinar uma configuração de barragem e dique que confira uma maior qualidade ao aço sem afetar a produtividade. Foram analisadas as condições do escoamento do distribuidor atual (sem modificadores de fluxo) da máquina de lingotamento contínuo 01 da Aperam Inox América do Sul e inserindo no mesmo, modificadores de fluxo (dique e barragem) em duas posições diferentes dentro do distribuidor.

\section{MATERIAL E MÉTODOS}

\subsection{Modelo Matemático}

No presente trabalho, as simulações matemáticas foram realizadas utilizando o software comercial ANSYS-CFX 14.0. O modelo de turbulência utilizado foi o modelo $\mathrm{K}-\varepsilon$ de Launder e Spalding (Patankar) [6]. Trata-se de um modelo de duas equações em que $\mathrm{K}$ e $\varepsilon$ representam, respectivamente, a energia cinética de turbulência e a taxa de dissipação da energia cinética de turbulência. De acordo com Daoud [7], a utilização desse modelo apresenta soluções adequadas e rápidas computacionalmente para várias aplicações industriais, inclusive em estudo de distribuidores. Ainda de acordo com Daoud [7], o modelo $\mathrm{K}-\varepsilon$ é o modelo de turbulência mais difundido em aplicações industriais, inclusive em estudo de distribuidores. As equações resolvidas foram as equações de conservação de massa, quantidade de movimento e de espécies para simular a injeção de traçador.

\subsection{Condições Simuladas}

Para um mesmo distribuidor, de 15 toneladas, foram simuladas as condições do escoamento no distribuidor com projeto atual e inserindo no mesmo modificadores de fluxo (dique e barragem) alterando as suas posições. Essas configurações estão esquematicamente mostradas na Figura 1 e são assim denominadas:

- Configuração 01 - distribuidor atual sem modificadores de fluxo;

- Configuração 02 - distribuidor com dique e barragem, sendo que o dique foi posicionado a $1.000 \mathrm{~mm}$ da entrada do aço líquido no distribuidor (tubo submerso), e a barragem a $200 \mathrm{~mm}$ do dique.

- Configuração 03 - distribuidor com dique e barragem, sendo que o dique foi posicionado a $792,5 \mathrm{~mm}$ da entrada do aço líquido no distribuidor (tubo submerso), e a barragem a $500 \mathrm{~mm}$ do dique.

\footnotetext{
* Contribuição técnica ao 450 Seminário de Aciaria - Internacional, 25 a 28 de maio de 2014, Porto Alegre, RS, Brasil.
} 


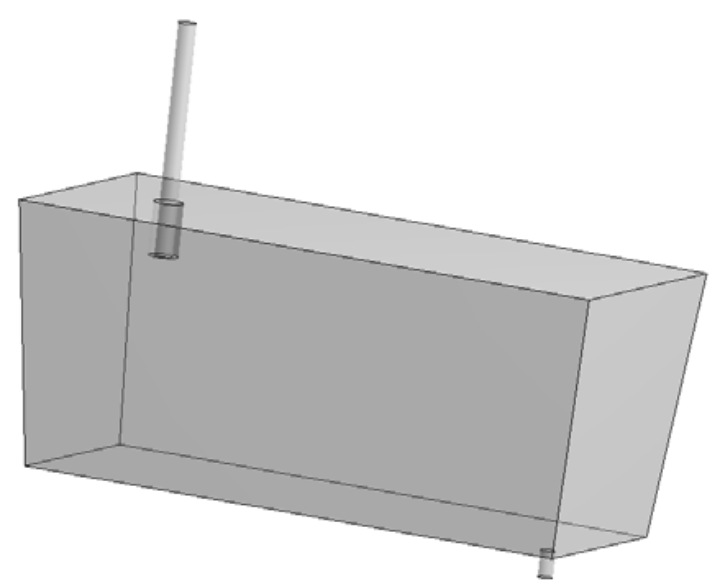

(a)
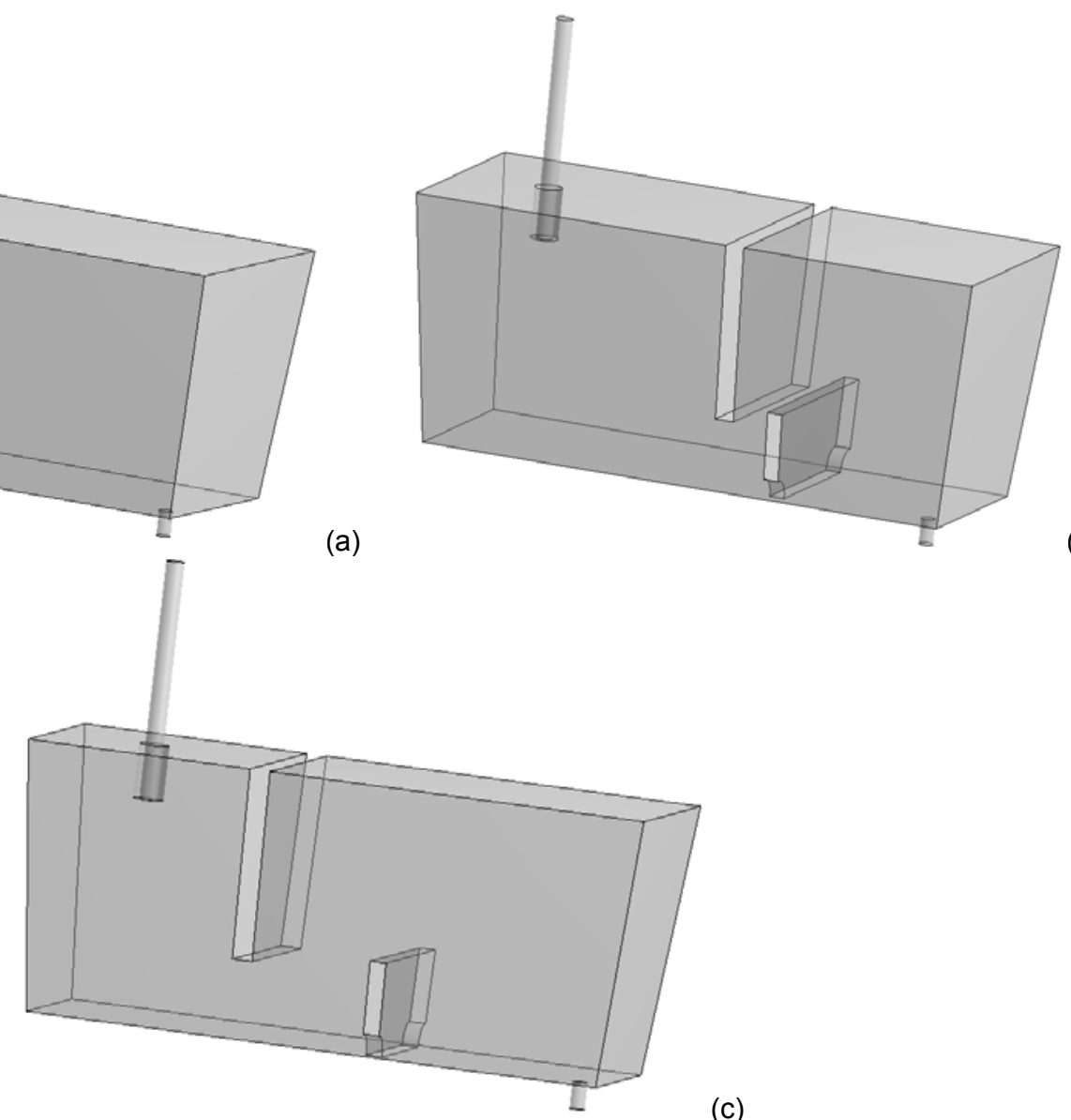

(b)

(c)

Figura 1. Desenho dos distribuidores mostrando a Configuração 01 (a), Configuração 02 (b) e Configuração 03 (c).

As simulações matemáticas foram desenvolvidas em três passos, sendo:

> Primeiro passo: simulação em estado estacionário. Nesse passo foi considerada uma taxa de alimentação de $23,6 \mathrm{Kg} / \mathrm{s}$ proveniente da panela. Nas resoluções das equações de conservação, foi definido como critério de convergência um resíduo médio de $1 \times 10^{-6}$ na solução e esquema de interpolação upwind. Em todas as simulações foi considerado o volume total do distribuidor, devido a entrada da válvula submersa estar deslocada $240 \mathrm{~mm}$ do eixo central do fundo do distribuidor, não sendo possível modelar com simetria. Não foi considerada a rugosidade das paredes e a condição de temperatura foi isotérmica.

$>$ Segundo passo: simulação no estado transiente. Nesse passo foram modeladas as curvas DTR. Os perfis estacionários modelados no primeiro passo foram usados como valores iniciais na simulação no estado transiente, sendo assim desnecessário refazer os cálculos das equações de conservação de massa e "momentum" para o aço. Somente foi resolvida a equação de conservação relativa à injeção do traçador. Um traçador foi injetado na entrada do tubo submerso durante um tempo de 2 segundos e sua concentração monitorada na entrada da válvula submersa.

$>$ Terceiro passo: análise da trajetória das partículas. Nesse passo foram criadas linhas de correntes (streamlines) para mostrar a trajetória das partículas, através do CFX-post, que é uma etapa de pós-processamento que permite visualizar os resultados obtidos no modelamento.

* Contribuição técnica ao 45 Seminário de Aciaria - Internacional, 25 a 28 de maio de 2014, Porto Alegre, RS, Brasil. 


\section{RESULTADOS E DISCUSSÃO}

\subsection{Análise do Escoamento}

A visualização dos perfis de velocidade é uma das maneiras mais eficientes de se perceber e avaliar a forma como o fluido está escoando dentro do domínio.

A Figura 2 apresenta os vetores de velocidade no plano do eixo da válvula submersa, considerando as três configurações citadas no item 2.2.

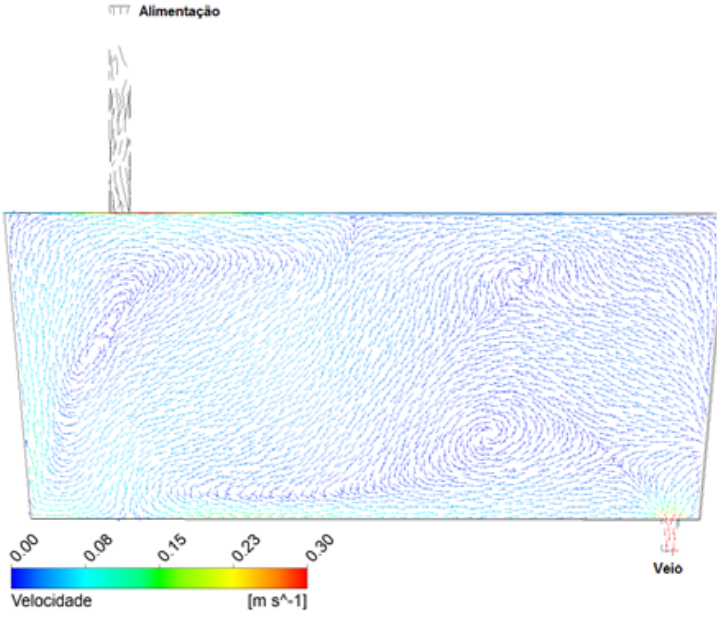

(a)

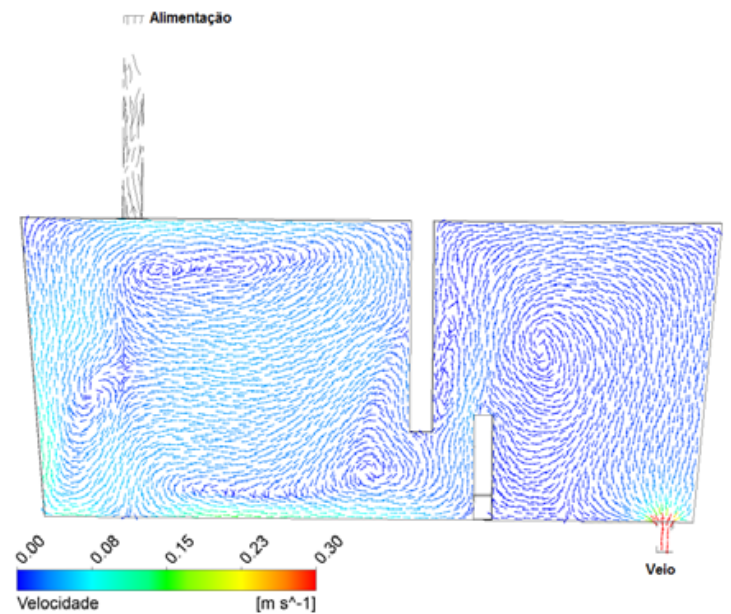

(b)

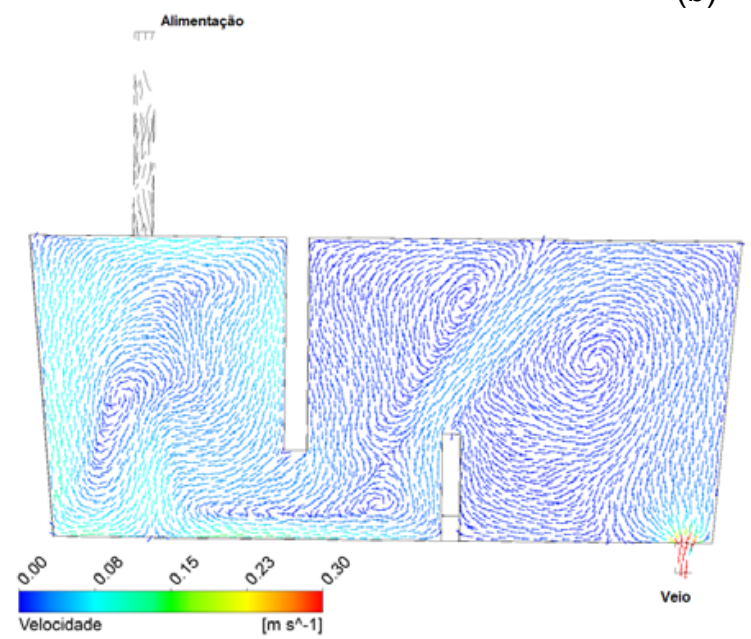

(c)

Figura 2. Vetores de velocidade no plano do eixo da válvula submersa para a Configuração 01 (a), Configuração 02 (b) e Configuração 03 (c).

Nota-se que a configuração 01 possuiu um fluxo descendente, o que confere ao mesmo uma característica de "curto circuito", que é um fenômeno que possui intervalo de tempo suficientemente baixo de forma a não permitir que as inclusões existentes sejam direcionadas para a superfície do aço líquido. Este comportamento potencializa a transferência de inclusões para a entrada da válvula submersa (molde).

Conforme pode se observado na Figura 2, a inserção de barragem e dique no distribuidor proporcionou uma melhoria significativa no fluxo de aço, passando a ter um fluxo ascendente, o qual permite que as inclusões sejam direcionadas para a superfície do aço líquido.

* Contribuição técnica ao 45 Seminário de Aciaria - Internacional, 25 a 28 de maio de 2014, Porto Alegre, RS, Brasil. 
A energia cinética de turbulência é também um importante parâmetro para estudar o comportamento do fluido, pois fornece uma estimativa do nível de turbulência em cada região do sistema. Nos casos de escoamento turbulento, a velocidade do fluido é composta por uma componente associada ao valor médio e outra relacionada à flutuação da velocidade em torno deste valor médio.

$\mathrm{Na}$ Figura 3 está apresentada a energia cinética de turbulência, na interface aço/escória. Essa análise é importante, pois permite verificar qual configuração terá maior turbulência nessa interface, o que pode provocar emulsificação e arraste de novas inclusões. Conforme pode ser observado na Figura 3, as Configurações 01 e 03 possuem as maiores energias de turbulência nessa interface.

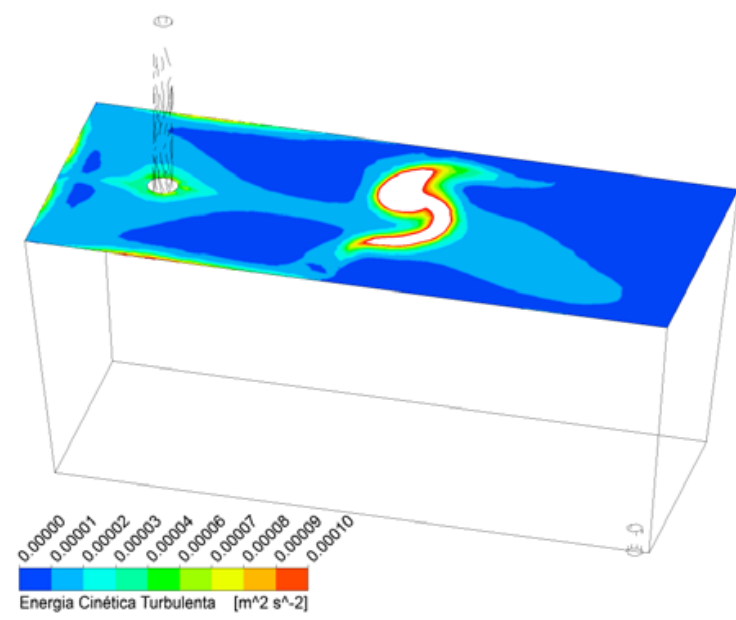

(a)

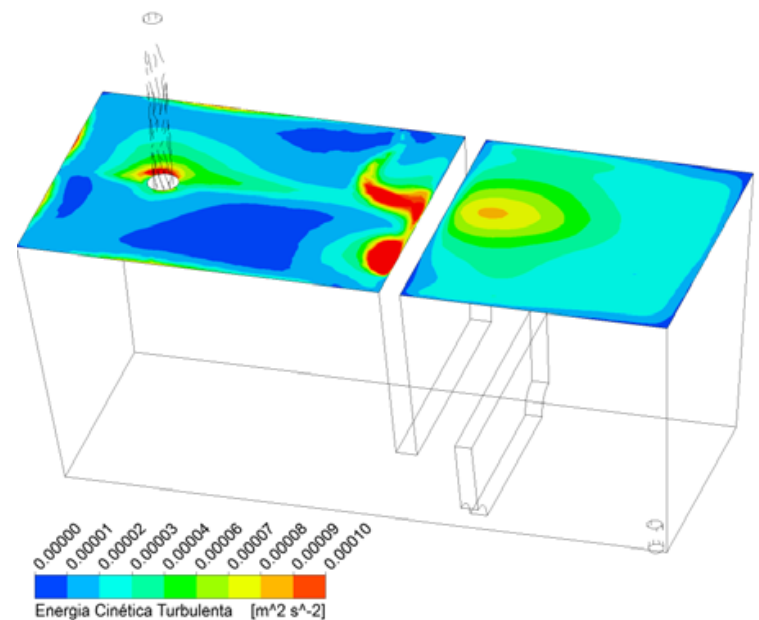

(b)

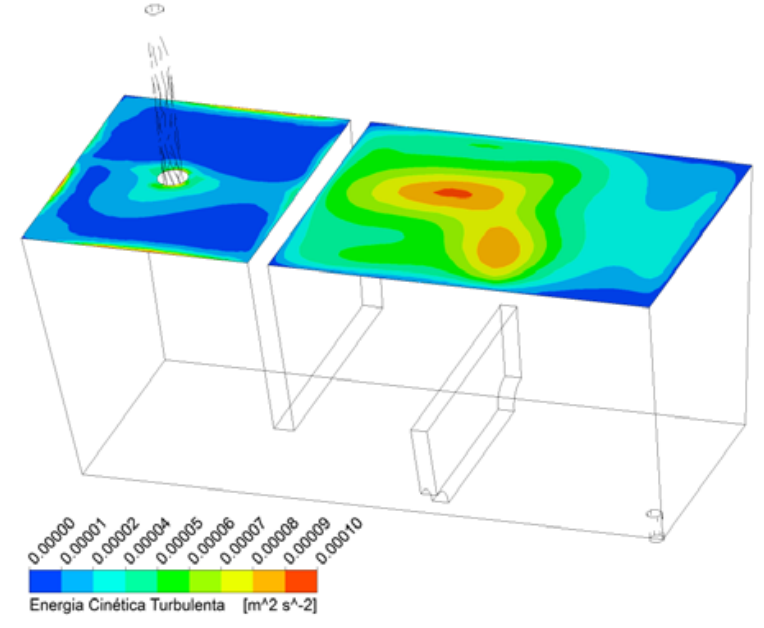

(c)

Figura 3. Contornos da energia de turbulência na interface aço/escória para a Configuração 01 (a), Configuração 02 (b) e Configuração 03 (c).

\subsection{Tempos e Volumes Característicos}

Para avaliar os tempos e volumes característicos foram analisadas as curvas DTR para cada simulação estudada.

De acordo com Szekely e llegbusi [8], o distribuidor no processo do lingotamento contínuo caracteriza-se pela existência de três zonas de fluxo distintas, definidas como:

$>$ Zona de fluxo pistonado: é a fração do volume total do distribuidor que apresenta velocidade pontual máxima, a qual determina o tempo mínimo de

* Contribuição técnica ao $45^{\circ}$ Seminário de Aciaria - Internacional, 25 a 28 de maio de 2014, Porto Alegre, RS, Brasil. 


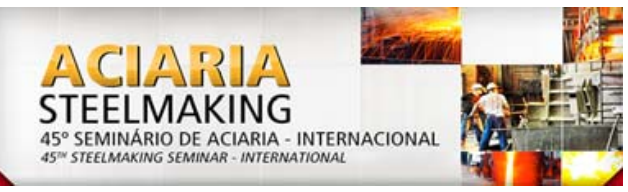

residência do metal líquido no distribuidor, sendo ideal um valor mais alto com relação à flotação das inclusões não-metálicas;

> Zona de mistura perfeita: é a fração que contribui para a eliminação dos gradientes de temperatura e de composição química no metal líquido. Essa região é caracterizada por um gradiente de velocidade causador de turbulência, o qual pode promover o arraste de inclusões não metálicas para dentro do aço líquido, distúrbios na flotação das inclusões não metálicas e o aumento da taxa de reoxidação do metal líquido;

- Zona de volume morto: é a fração de volume total do distribuidor que possui velocidade baixa o suficiente para ser considerada estagnada. Esta zona é indesejada, pois reduz efetivamente o volume útil do distribuidor, além de provocar a perda de temperatura do aço líquido e a segregação de elementos químicos. A presença dessa zona indica o uso ineficiente do volume do distribuidor. Pelo estudo de Sahai e Emi [9], esse volume seria a fração de material que fica no distribuidor acima de duas vezes o tempo de residência médio.

Os valores encontrados são apresentados na Tabela 1, onde se observa que a inserção da barragem e dique proporcionou uma melhoria significativa nos padrões de escoamento do distribuidor, sendo que a Configuração 02 apresentou a maior fração do volume pistonado e o maior tempo médio de residência.

Tabela 1. Comparação dos volumes característicos das simulações estudadas

\begin{tabular}{|c|c|c|c|c|}
\hline Configuração & $\begin{array}{c}\text { Volume de } \\
\text { mistura (\%) }\end{array}$ & $\begin{array}{c}\text { Volume } \\
\text { morto (\%) }\end{array}$ & $\begin{array}{c}\text { Volume } \\
\text { pistonado (\%) }\end{array}$ & $\begin{array}{c}\text { Tempo médio de } \\
\text { residência (s) }\end{array}$ \\
\hline Configuração 01 & 85,49 & 11,85 & 2,66 & 407 \\
\hline Configuração 02 & 56,08 & 15,31 & 28,61 & 550 \\
\hline Configuração 03 & 65,36 & 11,70 & 22,94 & 538 \\
\hline
\end{tabular}

\subsection{Trajetória das Partículas}

Para mostrar a trajetória de uma partícula dentro do domínio, o ANSYS CFX permite que sejam criadas linhas de corrente (streamlines). A elaboração desse tipo de figura é uma importante ferramenta na avaliação da maneira como as partículas do fluido se comportam dentro do domínio, servindo, por exemplo, para avaliar regiões de preferência de movimentação. A Figura 4 mostra as trajetórias das partículas dentro do distribuidor, iniciadas na alimentação (tubo submerso) até a saída (veio), onde se verifica que, na Configuração 01, várias partículas possuem trajetória preferencial para o veio (molde) enquanto que nas Configurações 01 e 03 essa preferência foi eliminada e as mesmas foram redirecionadas para a superfície do aço.

* Contribuição técnica ao 45 Seminário de Aciaria - Internacional, 25 a 28 de maio de 2014, Porto Alegre, RS, Brasil. 


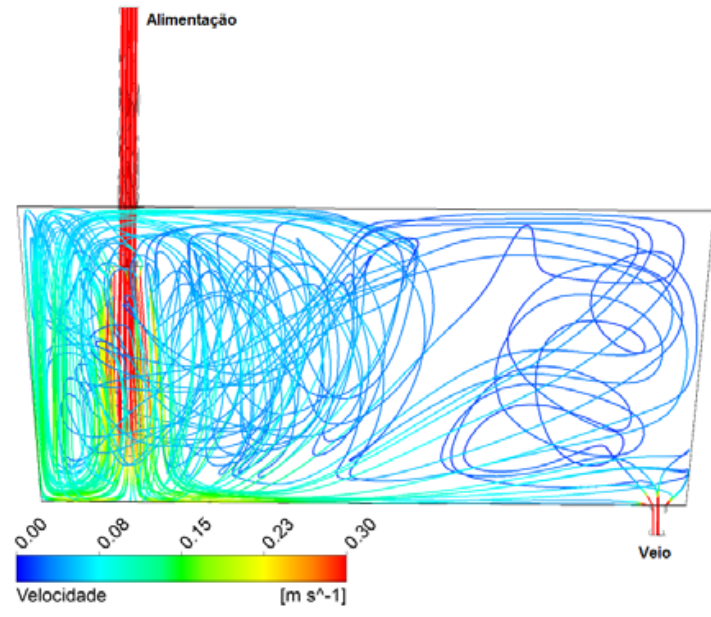

(a)

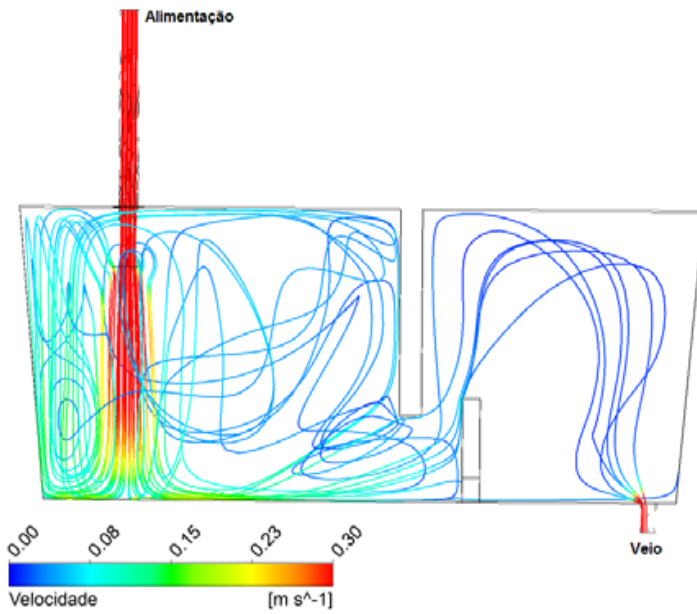

(b)

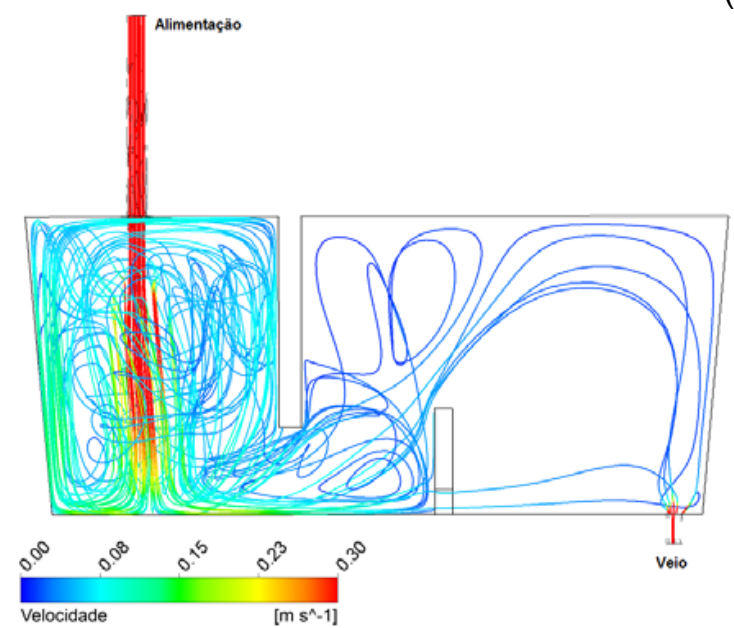

(c)

Figura 4. Linhas de corrente descrevendo a trajetória das partículas dentro do domínio da Configuração 01 (a), Configuração 02 (b) e Configuração 03 (c).

As curvas DTR fornecem informações relativas à distribuição dos tempos de permanência do aço no distribuidor, sendo possível quantificar as frações volumétricas características. A análise da trajetória das partículas ajuda a complementar os resultados da DTR, pois a análise da trajetória das partículas consiste em uma avaliação importante no processo de otimização da escolha das características do distribuidor de lingotamento.

\section{CONCLUSÃO}

Os resultados indicaram que a Configuração 02 apresentou os melhores resultados, o que poderá agregar maior qualidade ao aço produzido.

O distribuidor na Configuração 01 propicia alta turbulência e possui um escoamento característico de "curto-circuito", o que é prejudicial à qualidade do aço lingotado, promovendo uma menor flotação de inclusões, com maior turbulência em seu domínio.

Baseado nestes resultados sugere fazer mudanças no padrão de escoamento do aço da do distribuidor atual (Configuração 01), inserindo barragem e dique conforme descrito na Configuração 02, para os aços que tenham maior exigência de qualidade.

* Contribuição técnica ao 45 Seminário de Aciaria - Internacional, 25 a 28 de maio de 2014, Porto Alegre, RS, Brasil. 


\section{Agradecimentos}

Os autores agradecem ao Departamento de Engenharia Metalúrgica e de Materiais da Universidade Federal de Minas Gerais, pela estrutura de apoio oferecida aos alunos e a Empresa APERAM Inox América do Sul pela oportunidade de aperfeiçoamento técnico, profissional e pessoal, bem como pelos recursos financeiros que viabilizaram a elaboração deste trabalho.

\section{REFERÊNCIAS}

1 Barbosa FA, Araújo Filho GM, Tavares RP. Modelagens matemática e física do escoamento do aço líquido em diferentes projetos de distribuidor do lingotamento contínuo da Usiminas. Tecnologia em Metalurgia e Materiais. 2005; 1(4):34-39.

2 Wollmann AM, François MG, Vilela ACF, Joaquin BAS, Soares RB, Leal P. Estudos de fluxo no distribuidor de lingotamento contínuo de Aços Finos Piratini. In: $29^{\circ}$ Seminário sobre fusão, refino e solidificação dos metais; $11-13$ maio 1998; São Paulo, Brasil. São Paulo: ABM; 1998.

3 Morales RD, Lopez-Ramirez S, Palafox-Ramos J, Zacharias D. Numerical and modeling analysis of fluid and heat transfer of liquid steel in a tundish with different flow control devices. ISIJ International. 1999;33(5): 455-462.

4 Sinha A, Sahai Y. Mathematical modeling of inclusion transport and removal in continuous casting tundishes. ISIJ International. 1993;33(5):556-566.

5 Zhang L, Thomas BG. State of the art in evaluation and control of steel cleanliness. ISIJ International. 2003;43(3):271-291.

6 Patankar SV. Numerical heat transfer and fluid flow. Washington: McGraw Hill Book Company; 1980. p.197.

7 Daoud ILA. Estudo numérico do escoamento e do comportamento de inclusões nãometálicas em distribuidores de lingotamento contínuo de aço [Dissertação de Mestrado em Engenharia Metalúrgica]. Porto Alegre: Universidade Federal do Rio Grande do Sul; 2006. p.42.

8 Szekely J, llegbusi OJ. The Physical and Mathematical Modeling of Tundish Operations. New York: Springer-Verlag; 1988. p.111.

9 Sahai Y, Emi T. Melt Flow characterization in continuous casting tundishes. ISIJ international. 1996;36(6): 667-72.

* Contribuição técnica ao 45 Seminário de Aciaria - Internacional, 25 a 28 de maio de 2014, Porto Alegre, RS, Brasil. 